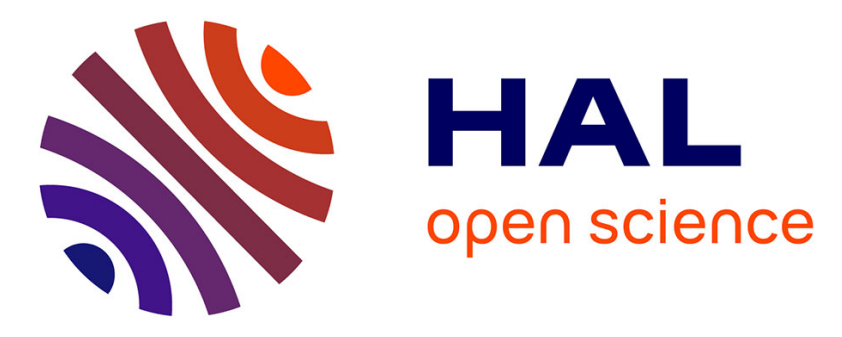

\title{
Catalytic light-triggered reduction promoted by a dithienylethene derivative
}

\author{
Amina Khettabi, Arkadiusz Grempka, Frederic Lafolet, Elarbi Chatir, Nicolas \\ Leconte, Marie-Noelle Collomb, Damien Jouvenot, Saioa Cobo
}

\section{To cite this version:}

Amina Khettabi, Arkadiusz Grempka, Frederic Lafolet, Elarbi Chatir, Nicolas Leconte, et al.. Catalytic light-triggered reduction promoted by a dithienylethene derivative. Chemistry - A European Journal, 2020, 26 (59), pp.13359-13362. 10.1002/chem.201905825 . hal-03064875

\section{HAL Id: hal-03064875 \\ https://hal.science/hal-03064875}

Submitted on 14 Dec 2020

HAL is a multi-disciplinary open access archive for the deposit and dissemination of scientific research documents, whether they are published or not. The documents may come from teaching and research institutions in France or abroad, or from public or private research centers.
L'archive ouverte pluridisciplinaire HAL, est destinée au dépôt et à la diffusion de documents scientifiques de niveau recherche, publiés ou non, émanant des établissements d'enseignement et de recherche français ou étrangers, des laboratoires publics ou privés. 


\title{
Catalytic light-triggered reduction promoted by a dithienylethene derivative
}

\author{
Amina Khettabi ${ }^{[a]}$, Arkadiusz Grempka ${ }^{[a]}$, Frederic Lafolet ${ }^{[b]}$, Elarbi Chatir ${ }^{[a]}$, Nicolas Leconte ${ }^{[a]}$, \\ Marie-Noelle Collomb [a], Damien Jouvenot ${ }^{[a]}$, Saioa Cobo * [a], [c]
}

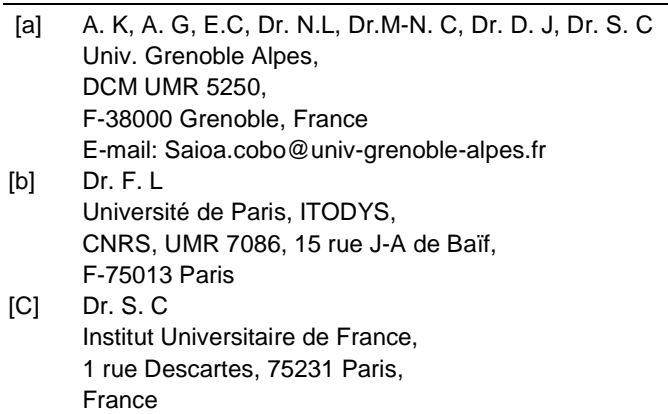

\begin{abstract}
A pyridinium substituted dithienylethene derivative was used for the first time as an efficient photo-reducing agent of two different substrates. This reaction exhibits high catalytic yields due to the continuous regeneration of the initial state of the photochromic molecule.
\end{abstract}

Efficient photochromic molecular materials able to trigger chemical or physical properties changes upon irradiation have attracted a lot of interest over the last years. ${ }^{1-6}$ The good resistance to fatigue and fast isomerization rates of dithienylethene (DTE) derivatives make them some of the most promising candidates for practical applications. DTE is a positive photochrom that undergoes a photocyclisation under UV light irradiation affording a molecule with increased $\pi$-conjugation. ${ }^{3,7-9}$ The reverse reaction leading to the DTE ring-opening is achieved by irradiation in the visible spectrum. The vast majority of studies carried out with DTE molecules have focused on the properties of the photo-isomerization process with a particular interest in the field of molecular electronics. ${ }^{10-16}$ In contrast, the redox properties of DTE derivatives have been much less explored. ${ }^{17-21}$ Nonetheless, several studies have described the photocyclisation of the DTE moiety through an oxidative process. Indeed, the oxidized open-ring DTE fragment can undergo an internal reorganization affording the closed isomer..$^{21-23}$ Launay et al..$^{23}$ have thoroughly studied the electrochemical cyclisation/cycloreversion of DTEs. They suggest that the oxidation of the open form generates a radical cation able to either dimerize or undergo a ring closure to form the closed radical cation through a disproportionation or an ECE mechanism. A few exceptions to the phenomenon have been observed where oxidation leads to the opening of the closed isomer, ${ }^{19,20,24,25}$ some of these being related to a disproportionation process. ${ }^{23,26,27}$ Feringa and Brown also rely on the disproportionation phenomenon to explain the opening reaction of a DTE derivative on a surface once the cationic closed DTE is formed. In this case, two DTE cationic molecules combine affording one in a high oxidation state and another in a low oxidation state, before undergoing an internal reorganization. The same authors also described the disproportionation processes in other electrochemical mechanisms in solution whenever a closed cationic DTE is present. ${ }^{28,29}$ Taking advantage of the possible disproportionation reaction of the cationic DTE derivatives, our approach is based on the redox processes between the thermodynamically unfavorable generated compounds and the substrate, in order to trap the highly reductive species thus shifting the equilibrium of such a reaction. This constitutes a novel approach to a typical light-promoted redox process, as it takes advantage of both the electro- and photochromic properties of DTEs.

For this purpose, a well-known DTE derivative bearing two pyridiniums entitie ${ }^{19,30}$ has been considered as its cationic nature provides unusual redox and optical properties $\left(\mathbf{1}^{2+}\right.$, Scheme 1$)$. Indeed, both isomers present a specific spectroscopic signature that allows to follow the photo-conversion processes between the open and closed forms using absorption spectroscopy (Figure S1). Moreover, the $1_{c}{ }^{2+}$ species can be considered as an oxidative or a reductive species due to its electrochemical behavior characterized by its two redox processes at $-0.52 \mathrm{~V}\left(\mathbf{1}^{2+} / \mathbf{1}^{+}\right)$and at $+1.05 \mathrm{~V}\left(\mathbf{1}_{\mathrm{c}}{ }^{3+\cdot} / \mathbf{1}_{\mathrm{c}}{ }^{2+}\right)$ vs. $\mathrm{Ag}^{+}\left(10^{-2} \mathrm{M}\right) \mid \mathrm{Ag}$, respectively (Figure S5). The irreversibility of the oxidation wave in the cyclic voltammogram of the closed-ring pyridinium DTE is due to the rapid ring-opening of the oxidized products. ${ }^{20}$ The large difference between the redox potentials makes the disproportionation processes thermodynamically unfavorable $\left(K_{d}=e^{-\Delta E / 25.69}\right) \cdot{ }^{31}$ However, if an equilibrium exists, as postulated by Le Chatellier's principle, the consumption of one of the products of the reaction will shift the equilibrium in favor of the disproportionation reaction. In that case any molecule for which the oxidation redox potential is located in the range of $+1.05 \mathrm{~V} /-0.52 \mathrm{~V}$ should be able to be reduced by $\mathbf{1}^{+}$, favoring the disproportionation reaction as a consequence.

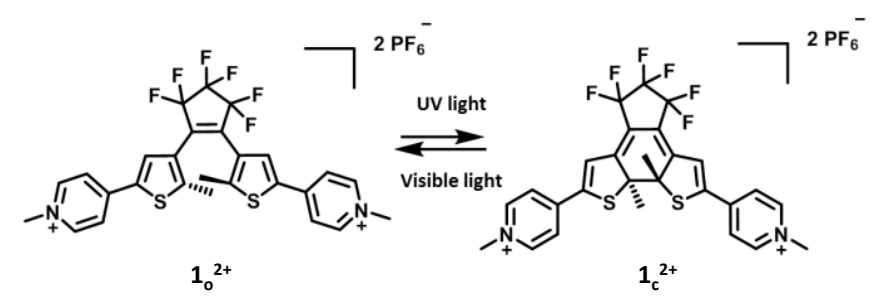

Schema 1. Photoisomerization process of $\mathbf{1}_{\mathrm{o}^{2+}} \mathbf{1}_{\mathrm{c}}{ }^{2+}$ couple.

In order to illustrate this phenomenon, the light-triggered reduction of iron (III) bisterpyridine ([Fe(tpy) $\left.\left.{ }_{2}\right]^{3+}\right)$ in the presence of the photochromic core $\mathbf{1}^{2+}$ is followed using absorption 
spectroscopy. Indeed, $\left[\mathrm{Fe}(\mathrm{tpy})_{2}\right]^{2+}$ has interesting optical and electrochemical properties: ${ }^{32}$ a) a very intense MLCT band (extinction coefficient $\sim 12000$ L. mol ${ }^{-1} . \mathrm{cm}^{-1}$ ) located at $550 \mathrm{~nm}$ (Figure $\mathrm{S} 1 \mathrm{~b}$ ), b) the $\mathrm{Fe}^{\mathrm{III} /} / \mathrm{Fe}^{\mathrm{Il}}$ redox potential is located at $+0.75 \mathrm{~V}$ vs. $\mathrm{Ag} \mathrm{Ag}^{+}$(Figure S4), well in the range for testing the photoreducing character of the considered DTE derivative.

The experiment proceeded as follows: a millimolar solution of $\left[\mathrm{Fe}(\mathrm{tpy})_{2}\right]^{2+}$ was quantitatively oxidized at $+0.9 \mathrm{~V}\left(1 \mathrm{e}^{-} /\right.$molecule $)$ and the evolution of its UV-vis absorption spectrum was recorded during the electrolysis. The initially deep purple solution, characterized by one main absorption band in the visible region at $550 \mathrm{~nm}$, was bleached during the electrochemical process to give a light-yellow solution. The UV-vis spectrum (Figure S1b) shows the disappearance of the visible MLCT band attributed to $\left[\mathrm{Fe}(\mathrm{tpy})_{2}\right]^{2+}$ and the shift of the UV-region bands from $333 \mathrm{~nm}$ to $353 \mathrm{~nm}$. This spectro-electrochemical experiment confirms a quantitative oxidation of $\left[\mathrm{Fe}(\mathrm{tpy})_{2}\right]^{2+}$ to $\left[\mathrm{Fe}(\mathrm{tpy})_{2}\right]^{3+}$ in solution. At this stage, the addition of one equivalent of $10^{2+}$ showed an increase in intensity of the bands located in the UV region and attributed to the open form of our molecule. Then, the solution containing a mixture of $\left[\mathrm{Fe}(\mathrm{tpy})_{2}\right]^{3+}$ and $\mathbf{1}^{2+}$ was irradiated with UV light and the absorption spectral changes were recorded. Instead of obtaining the sum of the absorption spectra of the expected closed form $\mathbf{1}^{2+}$ and $\left[\mathrm{Fe}(\mathrm{tpy})_{2}\right]^{3+}$, the spectral signature of the reduced iron (II) species emerged. During the irradiation time, the absorption peak at $550 \mathrm{~nm}$ ascribed to the MLCT band of the ferrous complex increases as well as the band at $650 \mathrm{~nm}$ attributed to the closed form of the DTE and reach their maximum, indicating that the photo-induced reduction of $\left[\mathrm{Fe}(\mathrm{tpy})_{2}\right]^{3+}$ occurs by action of the $1^{2+}$ photochromic couple (Figure 1 ).

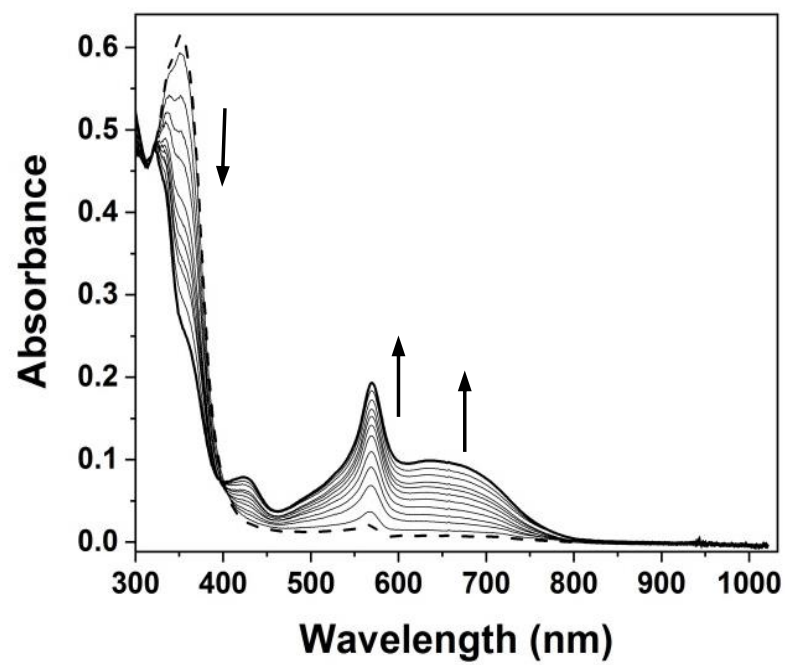

Figure 1. Evolution of UV-vis absorption spectra during the irradiation (366 nm) of a solution containing $10^{2+}$ and $\left[\mathrm{Fe}(\mathrm{tpy})_{2}\right]^{3+}$ in acetonitrile at $0.1 \mathrm{mM}$.

In order to further investigate the mechanism of this reaction, an equimolar amount of $\mathbf{1}_{\mathrm{c}}{ }^{2+}$ solution was added to a $\left[\mathrm{Fe}(\mathrm{tpy})_{2}\right]^{3+}$ solution in the dark. As the $\mathbf{1}_{\mathrm{c}}{ }^{2+}$ solution was added, the ringopening reaction of the photochromic molecule is evidenced by the decrease of the absorbance band at $650 \mathrm{~nm}$ attributed to $1_{\mathrm{c}}{ }^{2+}$ (Figure 2). In parallel, the reduction of the $\left[\mathrm{Fe}(\mathrm{tpy})_{2}\right]^{3+}$ to $\left[\mathrm{Fe}(\mathrm{tpy})_{2}\right]^{2+}$ can be observed with the increase of the MLCT absorption band at $550 \mathrm{~nm}$. The latter stops evolving when all $\mathbf{1}^{2+}$ has been consumed, generating a stationary state. Three clear isosbestic points are observed at 379, 452 and $566 \mathrm{~nm}$ confirming a confirming a strong interaction between the photochrom and metal complex (Figure 2 and S2).

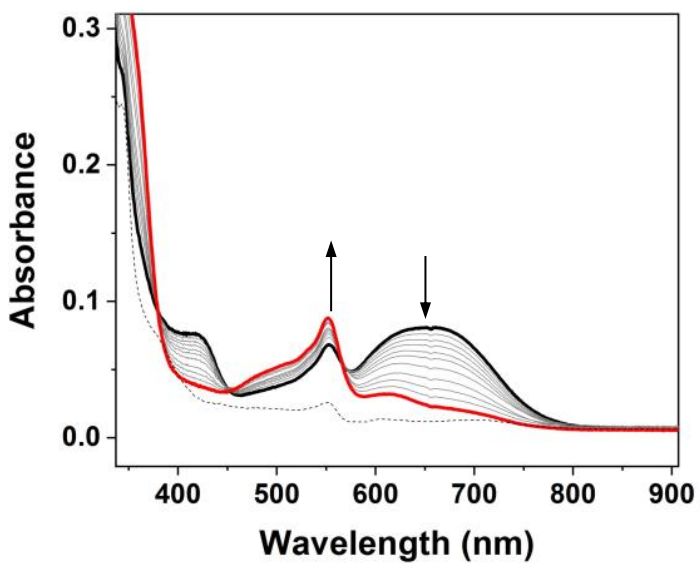

Figure 2. Evolution of UV-vis absorption spectra a) after addition of 1 equivalent of $1_{\mathrm{c}}{ }^{2+}$ to a $0.1 \mathrm{mM}$ solution of $\left[\mathrm{Fe}(\mathrm{tpy})_{2}\right]^{3+}\left(\mathrm{CH}_{3} \mathrm{CN}+0.1 \mathrm{M}\right.$ TBAP $)$

If the solution is then irradiated at $366 \mathrm{~nm}$, the regeneration of the closed form $1_{\mathrm{c}}{ }^{2+}$ enables the reduction of the remaining $\left[\mathrm{Fe}(\mathrm{tpy})_{2}\right]^{3+}$ (Figure S2).

Figure 3 represents the evolution of the band attributed to $1 \mathrm{c}^{2+}$ and $\left[\mathrm{Fe}(\mathrm{tpy})_{2}\right]^{3+}$ during the experiment. It can be clearly concluded that two equivalents of $\mathbf{1}_{\mathrm{c}}{ }^{2+}$ are necessary to reduce one equivalent of $\left[\mathrm{Fe}(\mathrm{tpy})_{2}\right]^{3+}$. Moreover, this experiment shows that the reductive character of $1_{c}{ }^{2+}$ can be triggered by light to reduce $\left[\mathrm{Fe}(\mathrm{tpy})_{2}\right]^{3+}$ as a substrate.

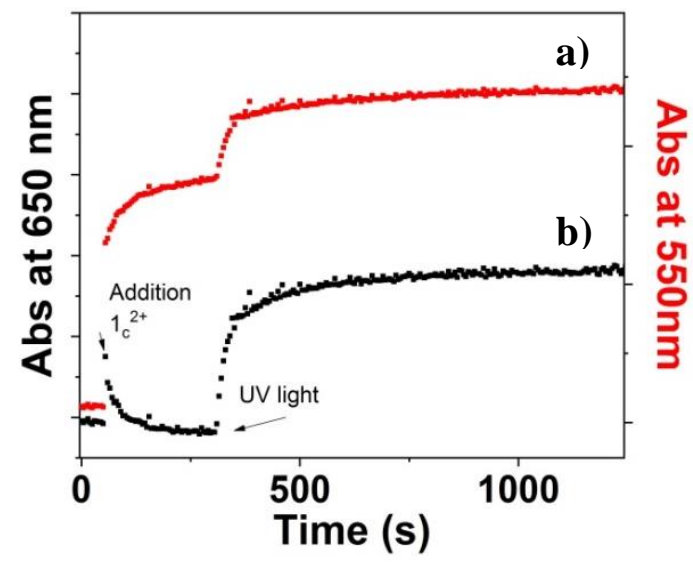

Figure 3. Evolution of the absorption intensity at $650 \mathrm{~nm}$ (a) and $550 \mathrm{~nm}$ (b) of a $0.1 \mathrm{mM}$ solution of $\left[\mathbf{F e}(\mathrm{tpy})_{2}\right]^{3+}\left(\mathrm{CH}_{3} \mathrm{CN}+0.1 \mathrm{M}\right.$ TBAP $)$. At $\mathrm{t}=0 \mathrm{~s} \mathbf{1}_{\mathrm{c}}{ }^{2+}$ is added to the solution, at $\mathrm{t}=300 \mathrm{~s}$ light is switched on $(366 \mathrm{~nm})$.

Based on these experimental data and elements from the literature, ${ }^{23,26,27}$ the proposed mechanism for a stochiometric 
reaction, can be described as follows: upon irradiation of the solution of $\left[\mathrm{Fe}(\mathrm{tpy})_{2}\right]^{3+}$ in the presence of $\mathbf{1 0}^{2+}$, the latter isomerizes to $1 \mathrm{c}^{2+}$. A disproportionation process can then occur: (i) two molecules of the dication $\mathbf{1}_{\mathrm{c}}{ }^{2+}$ leading to the monocation $\mathbf{1}_{\mathrm{c}}{ }^{+}$ and the radical trication $\mathbf{1}^{3+\cdot}$, (ii) a redox reaction between the reduced form and $\mathrm{Fe}(\mathrm{III})$, affording $\mathrm{Fe}(\mathrm{II})$ and $\mathbf{1}^{2+}$. (iii) once the radical cation $1 \mathrm{c}^{3+.}$ is produced, it isomerizes to $1 \mathrm{o}^{3+}$, (iv) which then subsequently oxidizes from another equivalent of $1_{c}{ }^{2+}$, and regenerates the original closed radical trication and the open dicationic species $1_{0}{ }^{2+}$. As a consequence of the continuous irradiation, $1_{0}{ }^{2+}$ isomerizes to the closed form and resets the system $(v)$.

The photo-triggered reduction was performed on another substrate featuring several redox processes in order to test its possible generalization. A nickel bis(benzoquinonediimine) complex, 2, showing 3 reversible redox waves and characteristic UV-vis spectra has been studied in presence of $\mathbf{1 0}^{2+}$ (Figure S3). The irradiation of a $\mathbf{2}^{2+}$ solution, obtained after a chemical oxidation with $\mathrm{AgSbF}_{6},{ }^{33}$ in the presence of a substoichiometric amount of $10^{2+}(7 \%)$ leads to the quantitative formation of $2^{+}$ $\left(E_{1 / 2}\left(2^{2+} / \mathbf{2}^{+}\right)=0 \quad \mathrm{~V}\right)$ (Figure 4). The characteristic bands corresponding to the dicationic molecule $2^{2+}(512$ and $769 \mathrm{~nm})$ disappear with the emergence of bands located at $569 \mathrm{~nm}$ and in the NIR at $904 \mathrm{~nm}$, characteristic of the monocationic molecule $2^{+}$. The second reduction $\left(E_{1 / 2}\left(2^{+} / \mathbf{2}\right)=-0.23 \mathrm{~V}\right)$ is not observed probably because this process overlaps with the reduction of $1 \mathrm{c}^{2+}$. The substoichiometric nature of the reaction tends to indicate a possible catalytic process.

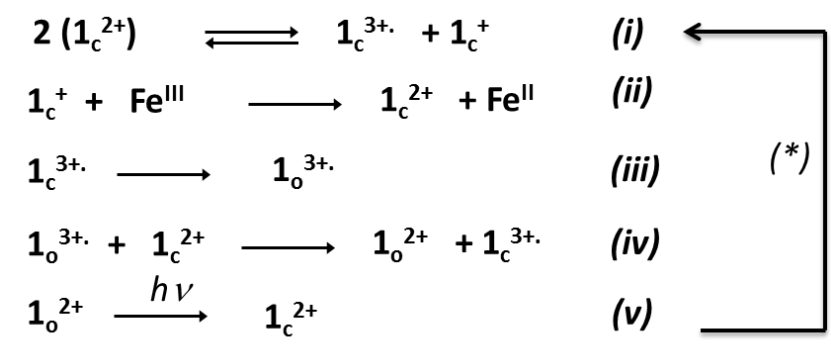

\section{$\left(^{*}\right)$ excess of $F e^{\prime l I}$}

Figure 4. Schematics of the photo-reduction process of $2^{2+}$ to $2^{+}$. UV-vis spectra of $\mathbf{2}^{2+}$ (plain line) and $\mathbf{2}^{+}$(dashed line) in presence of irradiated $10^{2+}(366 \mathrm{~nm})$ in $\mathrm{CH}_{2} \mathrm{Cl}_{2}$. [C $=0.03 \mathrm{mM}$ of $\mathbf{2}^{2+}$ and $0.002 \mathrm{mM}$ of $\mathbf{1}_{\mathrm{o}^{2+}}$.

In order to gain further insight into the photocatalytic process, the first reaction was performed and followed varying the number of equivalents $(0,0.1,0.3,0.5,0.7,1)$ of $1 \mathrm{o}^{2+}$ with respect to the iron complex (figure 5). Time dependence was observed with the number of equivalents. For 1 equivalent of $1_{0}{ }^{2+}$ present in solution, a quantitative conversion is obtained in less than $30 \mathrm{~min}$, whereas one hour is needed in the case of 0.5 equivalents. When the irradiation with UV light is performed with less than 0.5 equivalents of $1 \mathrm{o}^{2+}$, only a partial reduction of $\left[\mathrm{Fe}(\mathrm{tpy})_{2}\right]^{3+}$ is observed.
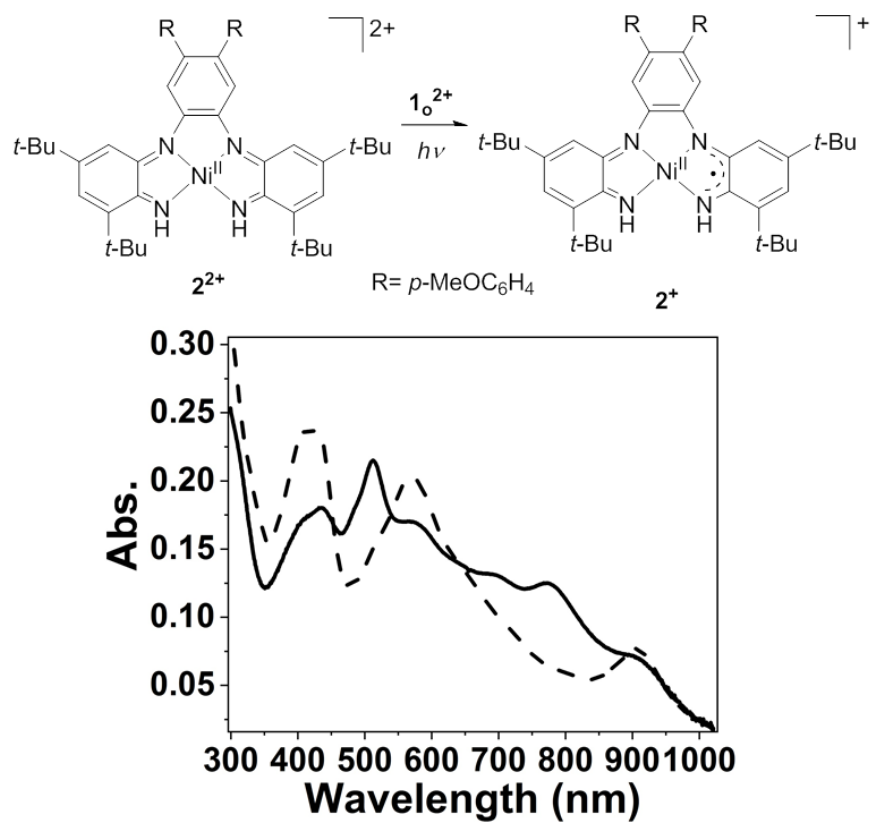

Figure 5. Photo-reduction of $\left[\mathrm{Fe}(\mathrm{tpy})_{2}\right]^{3+}$ followed by UV-vis spectroscopy at 8 min (open square), $15 \mathrm{~min}$ (full square), $30 \mathrm{~min}$ (open circle), $60 \mathrm{~min}$ (full circle) irradiation time induced by $0 \%, 10 \%, 30 \%, 50 \%, 70 \%, 100 \%$ of $10^{2+}$. The amount of the reduced form is determined by the absorbance at $550 \mathrm{~nm}$. [C]= $0.1 \mathrm{mM}$ of $\left[\mathrm{Fe}(\mathrm{tpy})_{2}\right]^{3+}$ in $\mathrm{CH}_{3} \mathrm{CN}$.

After one hour, a conversion of 56 and $80 \%$ of the iron reduction is reached in the presence of 0.1 and 0.3 equivalents of $10^{2+}$, respectively. However, when at least 0.5 equivalents of the photochromic molecule are added to the solution a complete reduction of the $\left[\mathrm{Fe}(\mathrm{tpy})_{2}\right]^{3+}$ to $\left[\mathrm{Fe}(\mathrm{tpy})_{2}\right]^{2+}$ is observed. This experiment confirms that the reduction of $\left[\mathrm{Fe}(\mathrm{tpy})_{2}\right]^{3+}$ by $1 \mathrm{o}^{2+}$ is a catalytic reaction, as $\mathbf{1}^{2+}$ can be regenerated under continuous irradiation. The photocatalytic cycle is summarized in the scheme 2. The first step of the cycle starts from the photoisomerization of $1_{0}{ }^{2+}$ into $1_{c}{ }^{2+}$. The presence of $\mathrm{Fe}$ (III) shifts the equilibrium of the reaction (i) towards the disproportionation reaction products $\left(\mathbf{1}^{+}\right.$ and $1_{c^{3+\cdot}}$ ). Consequently, Fe(III) is reduced by $1_{c}{ }^{+}$to afford Fe (II) and $1_{\mathrm{c}}{ }^{2+}$. In the meantime, $\mathbf{1}_{\mathrm{c}}{ }^{3+.}$ is converted into $1 \mathrm{o}^{3+.} .{ }^{20}$ Finally, the presence of $1_{o}{ }^{3+}$ and $1_{c}{ }^{2+}$ in solution leads to a redox reaction regenerating $1_{c}{ }^{3+.}$ and the starting reactant $1_{o}{ }^{2+}$. It should be pointed out that this catalytic behavior can be explained by the presence of an excess of iron (III). 


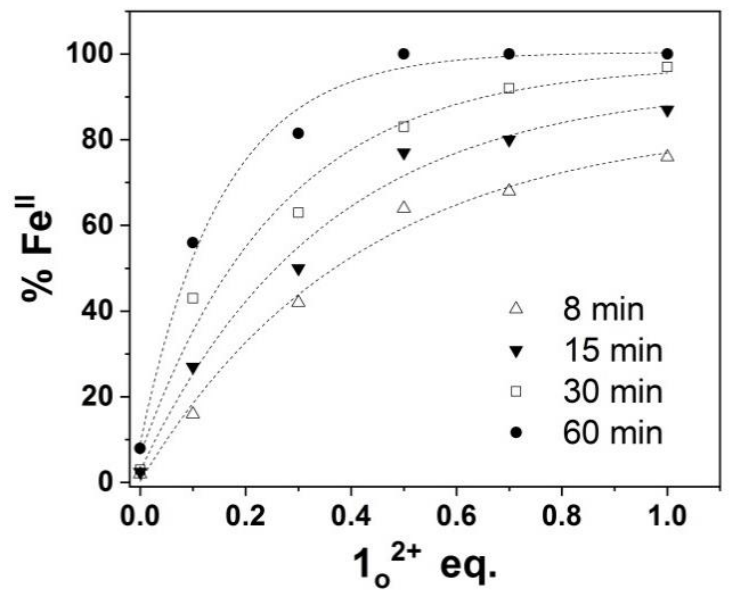

Figure 6. Photoreduction of $\left.[\mathrm{Fe}(\text { tpy })]^{3+}\right]^{3+}$ followed by UV/Vis spectroscopy at $8 \mathrm{~min}$ (open square), $15 \mathrm{~min}$ (full square), $30 \mathrm{~min}$ (open circle), $60 \mathrm{~min}$ (full circle) irradiation time induced by $0 \%, 10 \%, 30 \%, 50 \%, 70 \%, 100 \%$ of $1 \mathrm{O}_{2} \mathrm{C}$ The amount of the reduced form is determined by the absorbance at $550 \mathrm{~nm}$. [[Fe(tpy) $\left.\left.)_{2}\right]^{3+}\right]=0.1 \mathrm{~mm}$ in $\mathrm{CH}_{3} \mathrm{CN}$.

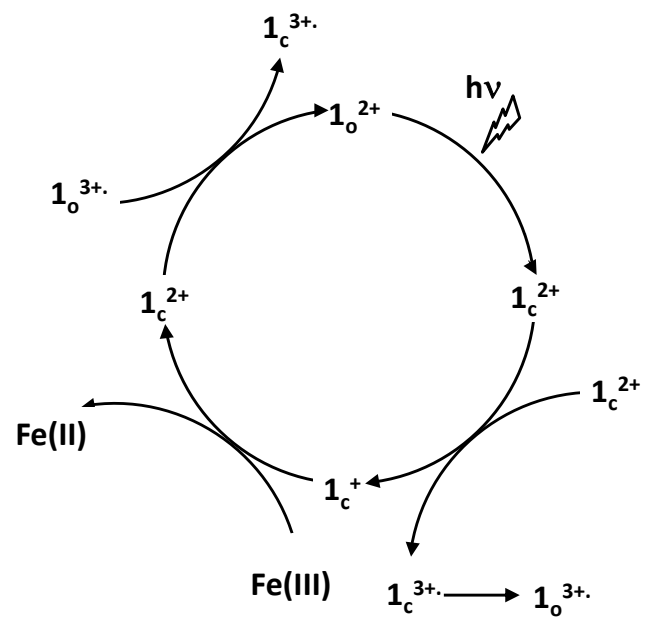

Scheme 2. Photocatalytic cycle of $\mathbf{1 o}^{2+}$ in presence of an excess of $\mathrm{Fe}$ (III).

In conclusion, we have shown for the first time the photo-reducing character of pyridinium substituted DTE derivatives. This reaction occurs through a catalytic mechanism based on a continuous regeneration of the initial $\mathbf{1}^{2+}$ state. It should be noted that other examples of photochromic materials able to induce catalytic reactions are still scarce and present quite modest quantum yields while in this case the reaction is quantitative. This result constitutes a real breakthrough in the field of photo-catalysis.

\section{Acknowledgements}

The authors wish to acknowledge the support the Institut Universitaire de France.

Keywords: Photo-reduction • dithienylethene $\cdot$ photochromism • catalytic reduction $\cdot$

(1) Bléger, D.; Hecht, S. Visible-Light-Activated Molecular Switches. Angew. Chem. Int. Ed. 2015, 54, 11338-11349. https://doi.org/10.1002/anie.201500628.

(2) Leydecker, T.; Herder, M.; Pavlica, E.; Bratina, G.; Hecht, S.; Orgiu, E.; Samorì, P. Flexible Non-Volatile Optical Memory Thin-Film Transistor Device with over 256 Distinct Levels Based on an Organic Bicomponent Blend. Nat. Nanotechnol. 2016, 11, 769-775. https://doi.org/10.1038/nnano.2016.87.

(3) Irie, M. I. Review Photochromism of Diarylethene Molecules and Crystals. Coord. Chem. Rev. 2010, 86, 472-483. https://doi.org/10.2183/pjab.86.472.

(4) Irie, M.; Fukaminato, T.; Matsuda, K.; Kobatake, S. Photochromism of Diarylethene Molecules and Crystals : Memories, Switches and Actuators. Chem. Rev. 2014, 114, 12174-12277.

(5) Kobatake, S.; Takami, S.; Muto, H.; Ishikawa, T.; Irie, M. Rapid and Reversible Shape Changes of Molecular Crystals on Photoirradiation. Nature 2007, 446 (7137), 778-781. https://doi.org/10.1038/nature05669.

(6) Roldan, D.; Kaliginedi, V.; Cobo, S.; Kolivoska, V.; Bucher, C.; Hong, W.; Royal, G.; Wandlowski, T. Charge Transport in Photoswitchable Dimethyldihydropyrene-Type SingleMolecule Junctions. J. Am. Chem. Soc. 2013, 135 (16), 5974-5977. https://doi.org/10.1021/ja401484j.

Tian, H.; Yang, S. Recent Progresses on Diarylethene Based Photochromic Switches. Chem. Soc. Rev. 2004, 33, 85. https://doi.org/10.1039/b302356g.

(8) Irie, M.; Fukaminato, T.; Matsuda, K.; Kobatake, S. Photochromism of Diarylethene Molecules and Crystals : Memories, Switches and Actuators. Chem. Rev. 2014, 114, 12174-12277.

(9) Terao, F.; Morimoto, M.; Irie, M. Light-Driven MolecularCrystal Actuators: Rapid and Reversible Bending of Rodlike Mixed Crystals of Diarylethene Derivatives. Angew. Chem. Int. Ed. 2012, 51, 901-904.

https://doi.org/10.1002/anie.201105585.

(10) Tsujioka, T.; Sasa, T.; Kakihara, Y. Nonvolatile Organic Memory Based on Isomerization of Diarylethene Molecules by Electrical Carrier Injection. Org. Electron. 2012, 13, 681686. https://doi.org/10.1016/j.orgel.2012.01.017.

(11) Uchida, K.; Yamanoi, Y.; Yonezawa, T.; Nishihara, H. Reversible On / Off Conductance Switching of Single Diarylethene. J. Am. Chem. Soc. 2011, 133, 9239-9241. https://doi.org/10.1021/ja203269t. 
(12) Katsonis, N.; Kudernac, T.; Walko, M.; Van Der Molen, S. J.; Van Wees, B. J.; Feringa, B. L. Reversible Conductance Switching of Single Diarylethenes on a Gold Surface. Adv. Mater. 2006, 18, 1397-1400.

https://doi.org/10.1002/adma.200600210.

(13) Hayakawa, R.; Higashiguchi, K.; Matsuda, K.; Chikyow, T.; Wakayama, Y. Optically and Electrically Driven Organic Thin Film Transistors with Diarylethene Photochromic Channel Layers. ACS Appl. Mater. Interfaces 2013, 5 (9), 3625-3630. https://doi.org/10.1021/am400030z.

(14) Kim, Y.; Hellmuth, T. J.; Sysoiev, D.; Pauly, F.; Pietsch, T.; Wolf, J.; Erbe, A.; Huhn, T.; Groth, U.; Steiner, U. E.; et al. Charge Transport Characteristics of Diarylethene Photoswitching Single-Molecule Junctions. Nano Lett. 2012, 12 (7), 3736-3742.

https://doi.org/10.1021/nl3015523.

(15) Tsujioka, T.; Masui, K.; Otoshi, F. Photocurrent Detection from Photochromic Diarylethene Film. Appl. Phys. Lett. 2004, 85, 3128-3130. https://doi.org/10.1063/1.1806270.

(16) Hayakawa, R.; Higashiguchi, K.; Matsuda, K.; Chikyow, T.; Wakayama, Y. Photoisomerization-Induced Manipulation of Single-Electron Tunneling for Novel Si-Based Optical Memory. ACS Appl. Mater. Interfaces 2013, 5 (21), 1137111376. https://doi.org/10.1021/am403616m.

(17) Gilat, S. L.; Kawai, S. H.; Lehn, J.-M. Light-Triggered Molecular Devices: Photochemical Switching Of Optical and Electrochemical Properties in Molecular Wire Type Diarylethene Species. Chem. - A Eur. J. 1995, 1 (5), 275284. https://doi.org/10.1002/chem.19950010504.

(18) Gorodetsky, B.; Samachetty, H. D.; Donkers, R. L.; Workentin, M. S.; Branda, N. R. Reductive Electrochemical Cyclization of a Photochromic 1,2-Dithienylcyclopentene Dication. Angew. Chem. Int. Ed. 2004, 43, 2812-2815. https://doi.org/10.1002/anie.200353029.

(19) Peters, A.; Branda, N. R.; Fraser, S.; Uni, V.; Uni, V.; Dri, V.; Va, C. Electrochromism in Photochromic Dithienylcyclopentenes. J. Am. Chem. Soc. 2003, 125, 3404-3405.

(20) Gorodetsky, B.; Branda, N. R. Bidirectional Ring-Opening and Ring-Closing of Cationic 1,2-Dithienylcyclopentene Molecular Switches Triggered with Light or Electricity. Adv. Funct. Mater. 2007, 17 (5), 786-796. https://doi.org/10.1002/adfm.200600902.

(21) Moriyama, Y.; Matsuda, K.; Tanifuji, N.; Irie, S.; Irie, M. Electrochemical Cyclization/Cycloreversion Reactions of Diarylethenes. Org. Lett. 2005, 7 (15), 3315-3318. https://doi.org/10.1021/ol051149o.

(22) Wesenhagen, P.; Areephong, J.; Fernandez Landaluce, T.; Heureux, N.; Katsonis, N.; Hjelm, J.; Rudolf, P.; Browne, W. R.; Feringa, B. L. Photochromism and Electrochemistry of a Dithienylcyclopentene Electroactive Polymer. Langmuir 2008, 24 (12), 6334-6342. https://doi.org/10.1021/la703999x.

(23) Guirado, G.; Coudret, C.; Hliwa, M.; Launay, J. Understanding Electrochromic Processes Initiated by Dithienylcyclopentene Cation-Radicals. J. Phys. Chem. B 2005, 109, 17445-17459.

https://doi.org/10.1021/jp052459r.

(24) Kleinwächter, M.; Teichmann, E.; Grubert, L.; Herder, M.; Hecht, S. Oxidative and Reductive Cyclization in Stiff Dithienylethenes. Beilstein J. Org. Chem. 2018, 14, 28122821. https://doi.org/10.3762/bjoc.14.259.

(25) Léaustic, A.; Anxolabehère, E.; Maurel, F.; Midelton, S.; Guillot, R.; Métivier, R.; Nakatani, K.; Yu, P. Photochromic and Reductive Electrochemical Switching of a Dithiazolylethene with Large Redox Modulation. Chem. - A Eur. J. 2011, 17, 2246-2255.

https://doi.org/10.1002/chem.201002451.

(26) Areephong, J.; Browne, W. R.; Katsonis, N.; Feringa, B. L. Photo- and Electro-Chromism of Diarylethene Modified ITO Electrodes-towards Molecular Based Read-Write-Erase Information Storage. Chem. Commun. 2006, 85 (37), 39303932. https://doi.org/10.1039/b608502d.

(27) Browne, W. R.; Kudernac, T.; Katsonis, N.; Areephong, J.; Hjelm, J.; Feringa, B. L. Electro- and Photochemical Switching of Dithienylethene Self-Assembled Monolayers on Gold Electrodes. J. Phys. Chem. C 2008, 112 (4), 11831190. https://doi.org/10.1021/jp0766508.

(28) Browne, W. R.; Jong, J. J. D. De; Kudernac, T.; Walko, M.; Lucas, L. N.; Uchida, K.; Esch, J. H. Van; Feringa, B. L. Oxidative Electrochemical Switching in Dithienylcyclopentenes, Part 2 : Effect of Substitution and Asymmetry on the Efficiency and Direction of Molecular Switching and Redox Stability. Chem. - A Eur. J. 2005, 11, 6430-6441. https://doi.org/10.1002/chem.200500163.

(29) Browne, W. R.; Jong, J. J. D. De; Kudernac, T.; Walko, M.; Lucas, L. N.; Uchida, K.; Esch, J. H. Van; Feringa, B. L. Oxidative Electrochemical Switching in Dithienylcyclopentenes, Part 1 : Effect of Electronic Perturbation on the Efficiency and Direction of Molecular Switching. Chem. - A Eur. J. 2005, 11, 6414-6429. https://doi.org/10.1002/chem.200500162.

(30) Gilat, S. L.; Kawai, S. H.; Lehn, J. Light-Triggered Molecular Devices: Photochemical Switching of Optical and Electrochemical Properties in Molecular Wire Type Diarylethene Species. Chem. - A Eur. J. 1995, 1 (5), 275.

(31) Richardson, D. E.; Taube, H. Determination of E2 ${ }^{\circ}-E 1^{\circ}$ in Multistep Charge Transfer by Stationary-Electrode Pulse and Cyclic Voltammetry: Application to Binuclear Ruthenium Ammines. Inorg. Chem. 1981, 20 (4), 12781285. https://doi.org/10.1021/ic50218a062.

(32) Lombard, J.; Leprêtre, J. C.; Chauvin, J.; Collomb, M. N.; Deronzier, A. Photoredox vs. Energy Transfer in a Ru(li)$\mathrm{Fe}$ (li) Supramolecular Complex Built with an Heteroditopic 
Bipyridine-Terpyridine Ligand. Dalt. Trans. 2008, 658-666. https://doi.org/10.1039/b710640h.

(33) Ciccione, J.; Leconte, N.; Luneau, D.; Philouze, C.; Thomas, F. Geometric and Electronic Structures of Nickel ( II ) Complexes of Redox Noninnocent Tetradentate Phenylenediamine Ligands. Inorg. Chem. 2016, 55, 649655. https://doi.org/10.1021/acs.inorgchem.5b01947. 
